Focussed on Steels and Composites for Engineering Structures

\title{
Residual Force Method for damage identification in a laminated composite plate with different boundary conditions
}

\author{
Amar Behtani, Samir Tiachacht \\ Laboratory of Mechanics, Structure, and Energetics, Mouloud Mammeri University of Tizi-Ouzou, Algeria. \\ amar.bebtani@ummto.dz; bttps://orcid.org/0000-0003-4503-0409 \\ samir.tiachacht@ummto.dz; https://orcid.org/0000-0002-3597-8725
}

Tawfiq Khatir

Department of Technology, University Centre of Naama - Salbi Ahmed, Naama, Algeria

Khatir_usto@yahoo.com; bttps:/ /orcid.org/0000-0003-3009-8371

Samir Khatir, Magd Abdel Wahab

Soete Laboratory, Faculty of Engineering and Architecture, Ghent University, Technologiepark. Zwijnaarde, Zwijnaarde, Belgium. Khatir.samir@hotmail.fr; https://orcid.org/0000-0002-8101-3633

Magd.AbdelWabab@UGent.be; https:/ /orcid.org/0000-0002-3610-865X

Brahim Benaissa

Design Engineering Laboratory, Toyota Technological Institute, Nagoya, Japan.

Benaissa@toyota-tiac.jp; bttps:/ /orcid.org/0000-0002-9472-9331

Mohand Slimani

Laboratory of Mechanics, Structure, and Energetics, Mouloud Mammeri University of Tizi-Ouzou, Algeria.

mohand.slimani@ummto.dz; bttps://orcid.org/0000-0003-4252-4892

\begin{abstract}
The strongest point about damage identification based on the dynamic measurements, is the ability to perform structural health evaluation globally. Researchers in the last few years payed more attention to damage indicators based on modal analysis using either frequencies, mode shapes, or Frequency Response Functions (FRFs). This paper presents a new application of damage identification in a cross-ply $\left(0^{\circ} / 90^{\circ} / 0^{\circ}\right)$ laminated composite plate based on Force Residual Method (FRM) damage indicator. Considering single and multiple damages with different damage levels. As well as investigating the SSSS and CCCC boundary conditions effect on the estimation accuracy. Moreover, a white Gaussian noise is introduced to test the challenges of the technique. The results show that the suggested FRM indicator provides accurate results under different boundary conditions, favouring the SSSS boundary condition than the CCCC for 3\% noise.
\end{abstract}

\section{OPEN $\bigcirc$ ACCESS}

Citation: Behtani, A., Tiachacht, S., Khatir, T., Hhatir, S., Abdel Wahab, M., Benaissa, B., Slimani, M., Residual Force Method for damage identification in a laminated composite plate with different boundary conditions, Frattura ed Integrità Strutturale, 59 (2022) 35-48.

Received: 28.08 .2021

Accepted: 02.10.2021

Published: 01.01.2022

Copyright: (C) 2022 This is an open access article under the terms of the CC-BY 4.0, which permits unrestricted use, distribution, and reproduction in any medium, provided the original author and source are credited. 
KEYWORDS. Damage quantification; RFM; Noise; Composite laminated plate.

\section{INTRODUCTION}

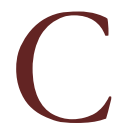

omposite materials become a cornerstone of modern material and are being used in almost every engineering discipline, like civil, infrastructure, aerospace engineering to name a few, due to their outstanding strength compared to their weight. However, composite materials are not immune to damage, and when it happens, whether due to fatigue or accidents, it can reduce their rigidity significantly. Therefore, researchers in the last decade developed new methods for damage identification dedicated to composite materials. In such methods, vibration-based structural responses are commonly used. Doebling et al. [1] presented a review of these approaches. We mention in this paper some of the noticeable literature, such as the study made by Khatri et al [2], in which the authors considered experimental analysis for damage identification in a complex structure, with an inverse problem formulation based on Particle Swarm Optimization (PSO). Ghannadi et al. [3] presented an approach based on the Multiverse Optimizer (MVO). Where two objective functions were used, namely the modal assurance criterion (MAC) and the modified total modal assurance criterion (MTMAC). Wand et al. [4] Suggested a neural network technique for damage identification refinement in the case of a suspension bridge. And Providakis et al. [5] used impedance-type measurements and error statistics to present a new damage identification approach in composite structures. Vahedian et al. [6] considered the case of multi-storey timber buildings and presented an improvement on the damage assessment by SFRP. And Tiachacht et al. [7] investigated a new modified indicator based on Cornwell Indicator (CI). This indicator was tested in different structures and the results suggested better accuracy than the peer methods. The frequency change-based approach was used in the classification of vibration-based damage detection techniques [8,9], a technique based on curvature mode shape [10], as well as another technique based on Modal Strain Energy [11]. Computational cost is often an issue in such methods. A quick damage identification method in the laminated composite plate using CI and Machine learning based Artificial Neural Network (ANN) was presented in Ref. [12]. The authors used Isogeometric Analysis (IGA) combined with damage indicator for damage localization and ANN for damage quantification. Different indicators were combined with laminated composite beams and plates in Refs. [13, 14].

Nobahari et al. [15] suggested an approach with the name: "Flexibility Strain Energy-Based Index (FSEBI)". For multiple damages identification, in both simple and complex cases. The efficiency of this method for multiple damage localization was shown in the results. Flexibility matrix for damage identification was investigated by [16]. This technique is efficient for damaged detection. However, the provided technique is experimentally validated. Ghannadi et al. [17] considered a variety of structures to investigate their new approach based on the Grey Wolf Optimization (GWO) algorithm. Using an objective function that combines the frequencies and mode shapes. The validation of the suggested methods is carried out in two experimental studies, namely a cantilever beam and a truss tower. Different optimization techniques were investigated for damage identification problems $[2,12,18-20]$, such as steel and composite plates, steel and composite beams, and complex structures.

In this paper, a laminated composite plate with three layers $\left(0^{\circ} / 90^{\circ} / 0^{\circ}\right)$ is considered for damage identification, using the residual force method with FEM. The structural response is studied under two kinds of boundary conditions, namely, fully simply supported (SSSS) and fully clamped plates (CCCC) to test the accuracy of FRM. Considering the measurement uncertainty up to $3 \%$ level, simulated by white Gaussian noise.

\section{METHODOLOGY}

\section{Finite Element Analysis of laminate plate}

7 his study is based on the First-order shear deformation theory (FSDT) [21]. In such a method, after material deformation, the effects of transverse shear strains cause the transverse to not remain perpendicular to the mid surface. $w$ is not function of the thickness coordinate $z$ because of the inextensibility of transverse normal.

Therefore, the displacement field of the FSDT function of time $t$ is written in the following form: 


$$
\left\{\begin{array}{l}
u(x, y, z, t)=u_{0}(x, y, t)+z \phi_{x}(x, y, t) \\
v(x, y, z, t)=v_{0}(x, y, t)+z \phi_{y}(x, y, t) \\
w(x, y, z, t)=w_{0}(x, y, t)
\end{array}\right.
$$

where $\left(u_{0}, v_{0}, w_{0}\right)$ is the displacement vector of a point on the plane $z=0, \phi_{x}$ is the rotations of a transverse normal around the $x$-axes and $\phi_{y}$ is the equivalent for the $y$-axes.

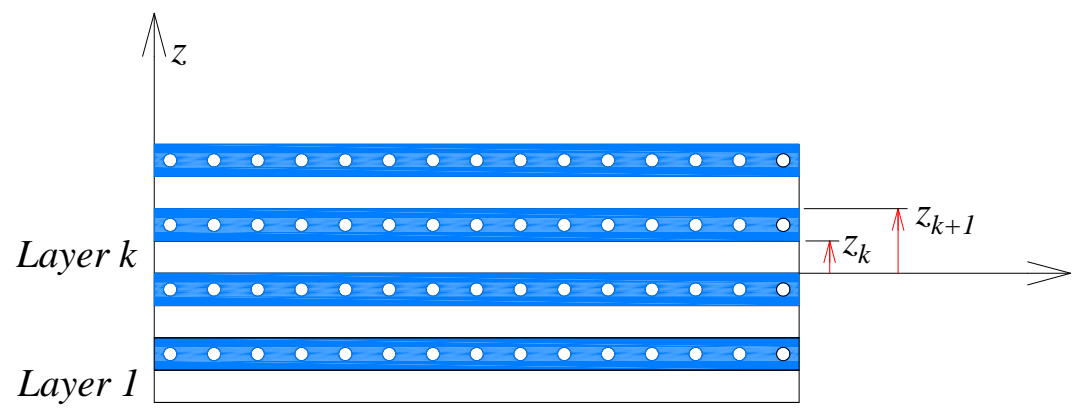

Figure 1: Laminated plate - organization of layers in the thickness direction.

The strain energy is:

$$
\begin{aligned}
U & =\frac{1}{2} \int_{A} u^{T} \int_{z}\left[B_{m}^{T} D^{k} B_{m}+B_{m}^{T} D^{k} B_{f}+B_{f}^{T} z D^{k} B_{m}+B_{f}^{T} z^{2} D^{k} B_{f}\right] d z u d A \\
& +\frac{1}{2} \int_{A} u^{T} \int_{z}\left[B_{c}^{T} D_{c}^{k} B_{c}\right] d z u d A
\end{aligned}
$$

The components of the stiffness matrix include the membrane-bending coupling part, are written as follows:

$$
K^{(e)}=K_{m m}^{(e)}+K_{m f}^{(e)}+K_{f m}^{(e)}+K_{f f}^{(e)}+K_{c c}^{(e)}
$$

where $K_{m m}^{e}$ is the stiffness matrix of the membrane part, and $K_{m f}^{e}, K_{f m}^{e}$ are the membrane-bending coupling components, $K_{f f}^{e}$ represent the bending component and $K_{c c}^{e}$ represent the shear component. These matrices are detailed as follows:

$$
\left\{\begin{array}{l}
K_{m m}^{(e)}=\sum_{k=1}^{n_{c}} \int_{A} B_{m}^{T} D_{k} B_{m}\left(z_{k+1}-z_{k}\right) d A \\
K_{m f}^{(e)}=\sum_{k=1}^{n_{c}} \int_{A} B_{m}^{T} D_{k} B_{f} \frac{1}{2}\left(z_{k+1}^{2}-z_{k}^{2}\right) d A \\
K_{f m}^{(e)}=\sum_{k=1}^{n_{c}} \int_{A} B_{f}^{T} D_{k} B_{m} \frac{1}{2}\left(z_{k+1}^{2}-z_{k}^{2}\right) d A \\
K_{f f}^{(e)}=\sum_{k=1}^{n_{c}} \int_{A} B_{f}^{T} D_{k} B_{f} \frac{1}{3}\left(z_{k+1}^{3}-z_{k}^{3}\right) d A \\
K_{c c}^{(e)}=\sum_{k=1}^{n_{c}} \int_{A} B_{c}^{T} D_{c} B_{c}\left(z_{k+1}-z_{k}\right) d A
\end{array}\right.
$$

Here $n_{c}$ represents the number of layers across the z-axes. 
There exist three $B$ matrices (membrane, the bending and the shear components), corresponding to the strain-displacements. They are described in detail as follows:

$$
\left\{\begin{array}{l}
B_{m}=\left[\begin{array}{lllll}
N_{, x} & 0 & 0 & 0 & 0 \\
0 & N_{, y} & 0 & 0 & 0 \\
N_{, y} & N_{, x} & 0 & 0 & 0
\end{array}\right] \\
B_{f}=\left[\begin{array}{lllll}
0 & 0 & 0 & N_{, x} & 0 \\
0 & 0 & 0 & 0 & N_{, y} \\
0 & 0 & 0 & N_{, y} & N_{, x}
\end{array}\right] \\
B_{c}=\left[\begin{array}{lllll}
0 & 0 & N_{, x} & N & 0 \\
0 & 0 & N_{, y} & 0 & N
\end{array}\right]
\end{array}\right.
$$

where $N_{, x}=\frac{\partial N}{\partial x}$ and $N_{, y}=\frac{\partial N}{\partial y}$

In this paper, we consider the dynamic version of the principle of virtual displacements. The equations of motion for the free vibration of symmetric cross-ply laminated plates can be expressed as:

$$
\left\{\begin{array}{l}
K_{s}\left(A_{55}\left(\frac{\partial^{2} w}{\partial x^{2}}+\frac{\partial \phi_{x}}{\partial x}\right)+A_{44}\left(\frac{\partial^{2} w}{\partial y^{2}}+\frac{\partial \phi_{x}}{\partial x}\right)\right)=I_{0} \frac{\partial^{2} w}{\partial t^{2}} \\
D_{11} \frac{\partial^{2} w}{\partial x^{2}}+D_{12} \frac{\partial^{2} \phi_{y}}{\partial x \partial y}+D_{66}\left(\frac{\partial^{2} \phi_{x}}{\partial y^{2}}+\frac{\partial^{2} \phi_{y}}{\partial x \partial y}\right)-K_{s} A_{55}\left(\frac{\partial w}{\partial x}+\phi_{x}\right)=I_{2} \frac{\partial^{2} \phi_{x}}{\partial t^{2}} \\
D_{12} \frac{\partial^{2} \phi_{x}}{\partial y^{2}}+D_{22} \frac{\partial^{2} \phi_{y}}{\partial y^{2}}+D_{66}\left(\frac{\partial^{2} \phi_{x}}{\partial x \partial y}+\frac{\partial^{2} \phi_{y}}{\partial x^{2}}\right)-K_{s} A_{44}\left(\frac{\partial w}{\partial y}+\phi_{y}\right)=I_{2} \frac{\partial^{2} \phi_{y}}{\partial t^{2}}
\end{array}\right.
$$

Here, $I_{0}$ and $I_{2}$ are the tensor components for the mass inertia, and they are defined as:

$$
I_{0}=\rho h ; I_{2}=\frac{\rho h^{3}}{12}
$$

where $\rho$ and $b$ are, respectively, the density and the total thickness of the composite plate. $A_{i j}$ and $D_{i j}$ are the extensional and bending stiffnesses, and they are expressed as in the following equations:

$$
\left\{\begin{array}{l}
A_{i j}=\sum_{k=1}^{N} \bar{Q}_{i j}^{(k)}\left(z_{k+1}-z_{k}\right) \\
D_{i j}=\sum_{k=1}^{N} \bar{Q}_{i j}^{(k)}\left(z_{k+1}^{3}-z_{k}^{3}\right)
\end{array}\right.
$$

where $\bar{Q}_{i j}^{(k)}$ is the stress-reduced stiffness matrix for the transformed material plane in each layer $k$.

In Eqn. (8), the matrix can be obtained as follows: 


$$
\bar{Q}=P Q_{m} P^{T}
$$

where $P$ is the transformation matrix given by:

$$
P=\left[\begin{array}{lllll}
\lambda^{2} & \mu^{2} & 0 & 0 & -\mu_{2} \\
\mu^{2} & \mu^{2} & 0 & 0 & \mu_{2} \\
0 & 0 & \lambda & \mu & 0 \\
0 & 0 & -\mu & \lambda & 0 \\
\mu \lambda & -\mu \lambda & 0 & 0 & \lambda^{2}-\mu^{2}
\end{array}\right]
$$

where $\lambda=\cos (\theta) ; \mu=\sin (\theta)$ and $\mu_{2}=\sin (2 \theta)$ and $Q_{m}$ is the stress-reduced stiffness for the material plane

$$
Q_{m}=\left[\begin{array}{lllll}
\chi_{1} & v_{12} \chi_{2} & 0 & 0 & 0 \\
v_{12} \chi_{2} & \chi_{2} & 0 & 0 & 0 \\
0 & 0 & G_{23} & 0 & 0 \\
0 & 0 & 0 & G_{13} & 0 \\
0 & 0 & 0 & 0 & G_{12}
\end{array}\right]
$$

Here $\chi_{1}=\frac{E_{1}}{\left(1-v_{12} v_{21}\right)}$; and $\chi_{2}=\frac{E_{2}}{\left(1-v_{12} v_{21}\right)}$, where $E_{1}$ is Young's modulus for a layer parallel to fibres. And $E_{2}$ is the equivalent Young's modulus for the layers that are perpendicular to fibres. On the other hand, $v_{12}$ and $v_{21}$ are Poisson's ratios. $G_{23}$ is the shear modulus for planes $2-3, G_{13}$ is the equivalent shear modulus for planes $1-3$, and $G_{12}$ represent the shear modulus for planes $1-2$.

The variables $w, \phi_{x}$ and $\phi_{y}$ can be expressed in the harmonic forms as follows:

$$
\left\{\begin{array}{l}
w(x, y, t)=\xi(x, y) e^{i \omega t} \\
\phi_{x}(x, y, t)=\Phi_{x}(x, y) e^{i \omega t} \\
\phi_{y}(x, y, t)=\Phi_{y}(x, y) e^{i \omega t}
\end{array}\right.
$$

and the equations of motion (6) become:

$$
\left\{\begin{array}{l}
K_{s}\left(A_{55}\left(\frac{\partial^{2} \xi}{\partial x^{2}}+\frac{\partial \Phi_{x}}{\partial x}\right)+A_{44}\left(\frac{\partial^{2} \xi}{\partial y^{2}}+\frac{\partial \Phi_{x}}{\partial x}\right)\right)=-I_{0} \omega^{2} \xi \\
D_{11} \frac{\partial^{2} \xi}{\partial x^{2}}+D_{12} \frac{\partial^{2} \Phi_{y}}{\partial x \partial y}+D_{66}\left(\frac{\partial^{2} \Phi_{x}}{\partial y^{2}}+\frac{\partial^{2} \Phi_{y}}{\partial x \partial y}\right)-K_{s} A_{55}\left(\frac{\partial \xi}{\partial x}+\Phi_{x}\right)=-I_{2} \omega^{2} \Phi_{x} \\
D_{12} \frac{\partial^{2} \Phi_{x}}{\partial y^{2}}+D_{22} \frac{\partial^{2} \Phi_{y}}{\partial y^{2}}+D_{66}\left(\frac{\partial^{2} \Phi_{x}}{\partial x \partial y}+\frac{\partial^{2} \Phi_{y}}{\partial x^{2}}\right)-K_{s} A_{44}\left(\frac{\partial \xi}{\partial y}+\phi_{y}\right)=-I_{2} \omega^{2} \Phi_{y}
\end{array}\right.
$$

In which $\omega$ is natural frequency. 


\section{Residual forces}

In this section, we explore structural damage identification based on the residual forces, details about residual forces can be found in Ref. [22]. In such approaches, the structure is divided into small elements via the finite element method, and the damage index of each element is expressed as the change of the rigidity i.e.:

$$
[\Delta K]_{i}^{e}=\left(\left[K^{u}\right]_{i}^{e}-\left[K^{d}\right]_{i}^{e}\right)=\alpha_{i}\left[K^{u}\right]_{i}^{e}
$$

where $\left[K^{u}\right]_{i}^{e}$ and $\left[K^{d}\right]_{i}^{e}$ are the elementary matrices of the undamaged and damaged structures, respectively. In the above equation, Eqn. (14), $[\Delta K]_{i}^{e}$ is the difference in stiffness, and $\alpha$ is a value between 0 and 1 , which indicates a loss of rigidity in each element. In other words, for undamaged elements, $\alpha$ is equal to 0 , and to 1 in fully damaged elements. In this study, we assume that the damage does not affect the mass matrix of a damaged structure, therefore the rigidity matrix of the damaged element is expressed as follows:

$$
\left\{\begin{array}{l}
{[\Delta M]=0} \\
{[\Delta K]_{j}^{e}=\alpha_{j}\left[K^{u}\right]_{j}^{e} \quad(j=1, \ldots, m)}
\end{array}\right.
$$

and the modal residual force vector is expressed by this equation:

$$
\{R\}_{i}=[\Delta K]\left\{\varphi^{d}\right\}_{i}=\{\Delta f\}_{i}=\left[\{\Delta\}_{1}^{e}\{\Delta f\}_{2}^{e} \cdots\{\Delta f\}_{m}^{e}\left\{\begin{array}{c}
\alpha_{1} \\
\alpha_{2} \\
\vdots \\
\alpha_{m}
\end{array}\right\}\right]=[F]_{i}\{\alpha\}
$$

As consequence, Eqn. (16) can be represented in a matrix form by the following expression:

$$
[F]\{\alpha\}=\{R\}
$$

The coefficient matrix $[F]$ is:

$$
\{F\}_{i j}=\left[K^{u}\right]_{j}^{e}\left\{\varphi^{d}\right\}_{i j}^{e}
$$

Here, $\{F\}_{i j}$ is the force vector in the actual node $i^{\text {th }}$ on the $j^{\text {th }}$ element, written in the global coordinates.

The vector of residual force modal is expressed in this manner:

$$
\{R\}_{i}=\left([K]-\lambda_{i}^{d}[M]\right)\left\{\varphi^{d}\right\}_{i}
$$

and Eqn. (17) is rewritten in this manner:

$$
\left[\begin{array}{cccc}
\{F\}_{11} & \{F\}_{12} & \cdots & \{F\}_{1 m} \\
\{F\}_{21} & \{F\}_{22} & \cdots & \{F\}_{2 m} \\
\vdots & \vdots & \ddots & \vdots \\
\{F\}_{n 1} & \{F\}_{n 2} & \cdots & \{F\}_{n m}
\end{array}\right]\left\{\begin{array}{c}
\alpha_{1} \\
\alpha_{2} \\
\vdots \\
\alpha_{m}
\end{array}\right\}=\left\{\begin{array}{c}
\{R\}_{1} \\
\{R\}_{2} \\
\vdots \\
\{R\}_{n}
\end{array}\right\}
$$


Here, $n$ is the number of modes. And $m$ is the number of elements. And the damage indicators are computed through the system of equations Eqn. (20)

$$
\left\{\begin{array}{c}
\alpha_{1} \\
\alpha_{2} \\
\vdots \\
\alpha_{m}
\end{array}\right\}=\left[\begin{array}{cccc}
\{F\}_{11} & \{F\}_{12} & \cdots & \{F\}_{1 m} \\
\{F\}_{21} & \{F\}_{22} & \cdots & \{F\}_{2 m} \\
\vdots & \vdots & \ddots & \vdots \\
\{F\}_{n 1} & \{F\}_{n 2} & \cdots & \{F\}_{n m}
\end{array}\right]^{+}\left\{\begin{array}{c}
\{R\}_{1} \\
\{R\}_{2} \\
\vdots \\
\{R\}_{n}
\end{array}\right\}
$$

\section{NUMERICAL EXAMPLES}

\section{A square laminated $\left(0^{\circ} / 90^{\circ} / 0^{\circ}\right)$ plates}

o investigate the performance of the suggested method, we consider an example of square cross-ply laminated plates. In this study, we assume that all layers of the laminate have the same thickness and density, and made of linearly elastic composite material, with the following properties for each layer: $E_{1} / E_{2}=40, G_{12}=G_{13}=0.6 E_{2}$; $G_{23}=0.5 E_{2} ; v_{12}=0.25$. Subscripts 1 denote the direction parallel to fibre orientation in a layer and 2 represent the perpendicular direction to the fibre.

Considering that the measurement is performed clockwise, the ply angle is positive of each layer from the global $x$-axis to the fibre direction, and negative if measured anti-clockwise. we consider a mesh of $10 \times 10$ (100 elements) as shown in Fig. 2. And to obtain the natural frequencies and mode shapes, the eigenproblem is solved using MATLAB. We compare our results to those published by Ferreira and Fasshauer [23] and [24], considering the same shear correction factors, as well as the nondimensionalized natural frequencies.
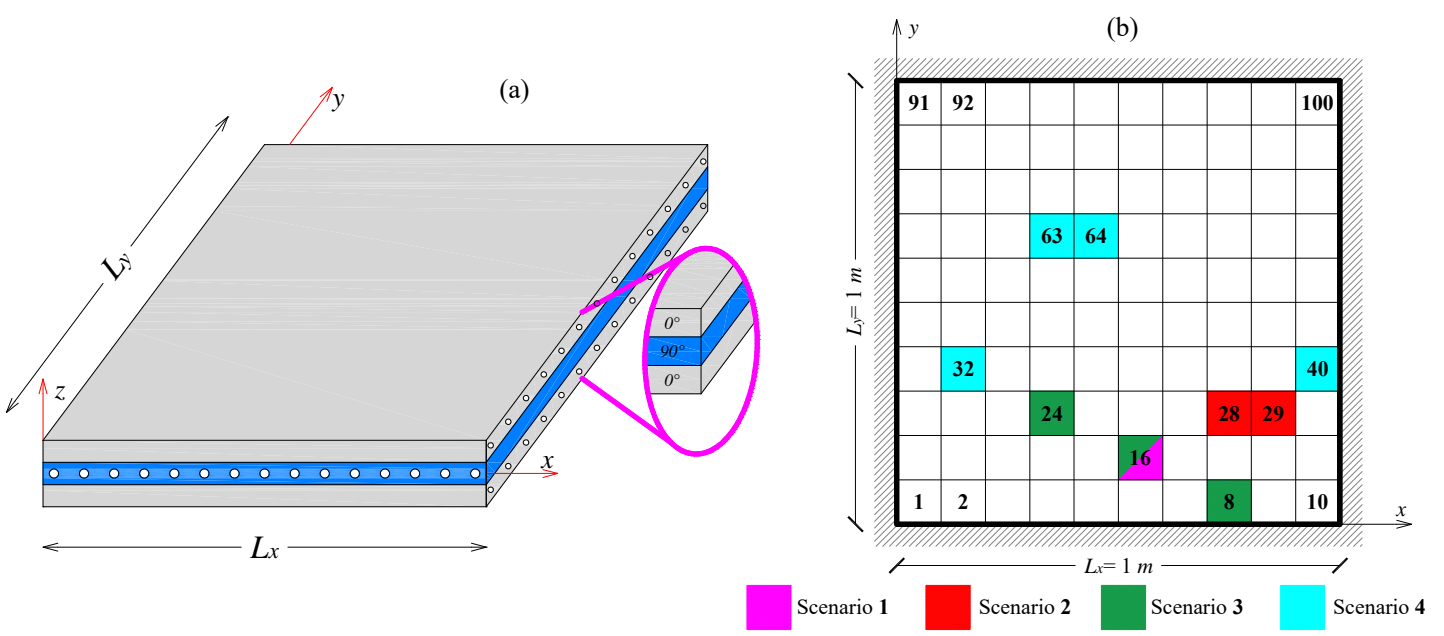

Figure 2: (a) A cross-ply $\left(0^{\circ} / 90^{\circ} / 0^{\circ}\right)$ square composite plate and (b) Discretized square isotropic plate with two damage scenarios.

The Shear correction factor is considered as $K_{s}=\pi^{2} / 12$, and the dimensionless natural frequency is given by: $\bar{\omega}=\omega\left(b^{2} / \pi^{2}\right) \sqrt{\rho h / D_{0}}$ where $D_{0}=E_{2} h^{3} / 12\left(1-v_{12} v_{21}\right)$. We also consider in this study, two damage scenarios, simulated by reducing the global stiffness of individual element in the following manner:

$$
K^{d}=\sum_{e=1}^{\text {nele }}(1-\alpha) K^{e}
$$

Here, $\alpha$ represents the damage ratio. $K^{d}$ is the global stiffness matrix representing the damaged structures. Finally, $K^{e}$ is the stiffness matrix of the $\mathrm{e}^{\text {th }}$ element. 
Considering three-ply $\left(0^{\circ} / 90^{\circ} / 0^{\circ}\right)$ clamped CCCC square, with laminated plates of thickness to span ratios $t / b=0.2$ and $a / b=1$, Tab. 2 shows the convergence results of dimensionless natural frequencies.

To validate the proposed damage identification approach, we consider four damage scenarios. The first scenario has one damage, and two damages in the second scenario and two other scenarios has three and four damages, respectively. Details of each damage case are shown in Tab. 1. And the corresponding natural frequencies are shown in Tab. 2. Fig. 3 shows the first four mode shapes of the cross-ply $\left(0^{\circ} / 90^{\circ} / 0^{\circ}\right)$ square composite plate under SSSS boundary conditions.

\begin{tabular}{ccccc}
\hline & Scenario 1 & Scenario 2 & Scenario 3 & Scenario 4 \\
& & & 8 & 32 \\
Element No & \multirow{2}{*}{16} & 28 & 16 & 40 \\
& & 29 & 24 & 63 \\
& & 5 & 15 & 64 \\
\hline \multirow{2}{*}{ Severity \% } & \multirow{2}{*}{15} & 5 & 10 & 5 \\
& & & & 5 \\
& & & & 10 \\
\hline
\end{tabular}

Table 1: Damage scenarios.

\begin{tabular}{ccccccc}
\hline \multirow{5}{*}{ Intact } & Mode & 1 & 2 & 3 & 4 & 5 \\
& {$[23] 10 \times 10$} & 3.5479 & 5.8947 & 7.3163 & 8.6545 & 9.7538 \\
& {$[24]$} & 3.5939 & 5.7691 & 7.3972 & 8.6876 & 9.1451 \\
& Present $10 \times 10$ & 3.5479 & 5.8947 & 7.3163 & 8.6545 & 9.7538 \\
\hline \multirow{4}{*}{ Damaged } & Scenario 1 & 3.5425 & 5.8934 & 7.3093 & 8.6516 & 9.7514 \\
& Scenario 2 & 3.5470 & 5.8933 & 7.3162 & 8.6541 & 9.7518 \\
& Scenario 3 & 3.5410 & 5.8885 & 7.3048 & 8.6377 & 9.7461 \\
& Scenario 4 & 3.5464 & 5.8905 & 7.3102 & 8.6455 & 9.7392 \\
\hline
\end{tabular}

Table 2: Naturel frequencies of undamaged and damaged laminate plate structure SSSS.
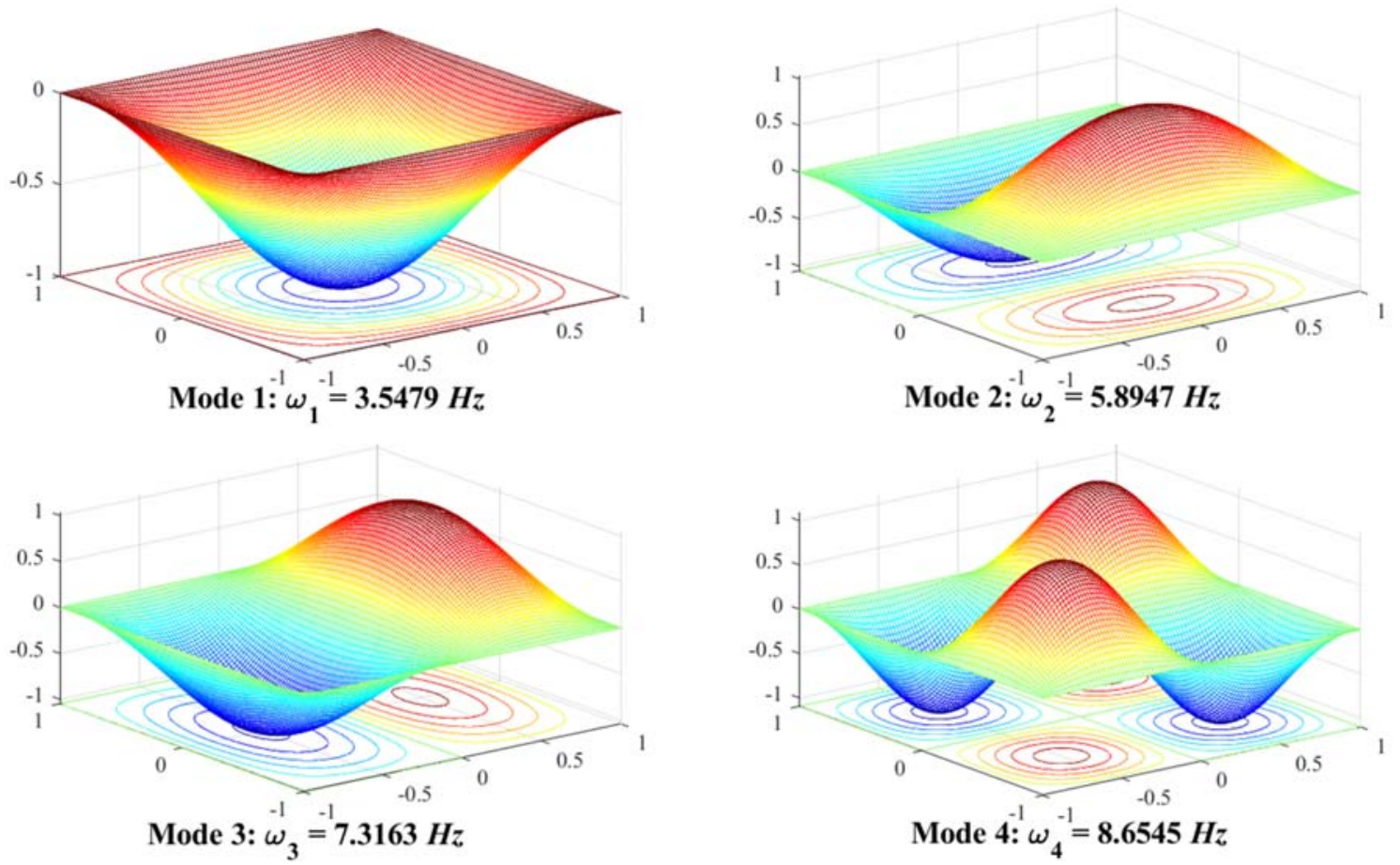

Figure 3: The first four mode shapes of the cross-ply $\left(0^{\circ} / 90^{\circ} / 0^{\circ}\right)$ fully simply supported square composite plate SSSS. 


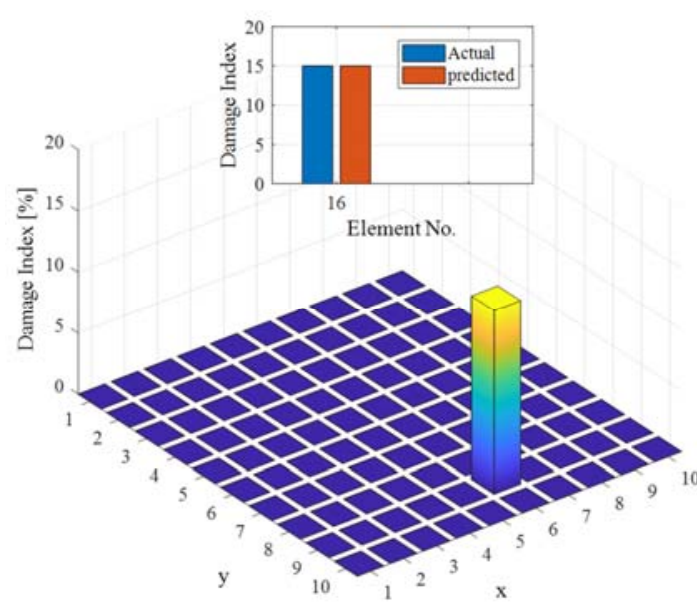

(a) Noise-free.

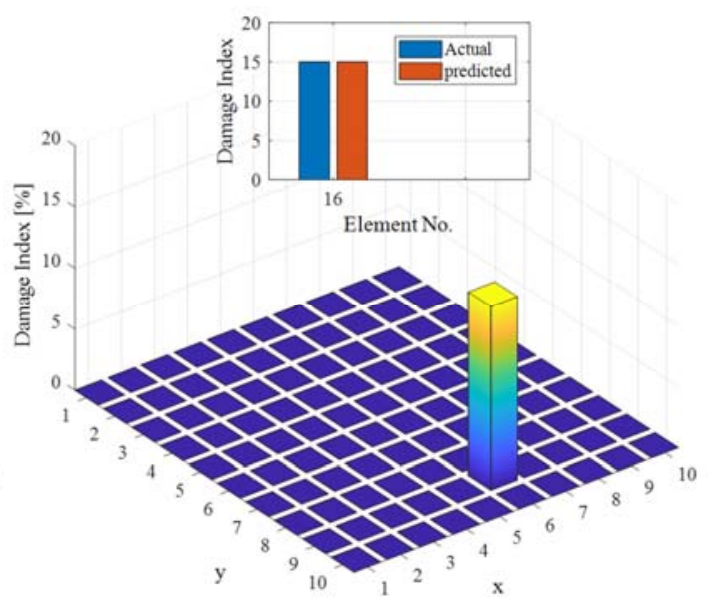

(b) Noise 3\%.

Figure 4: Damage index for all elements of the cross-ply $\left(0^{\circ} / 90^{\circ} / 0^{\circ}\right)$ square composite plate SSSS - Scenario 1.

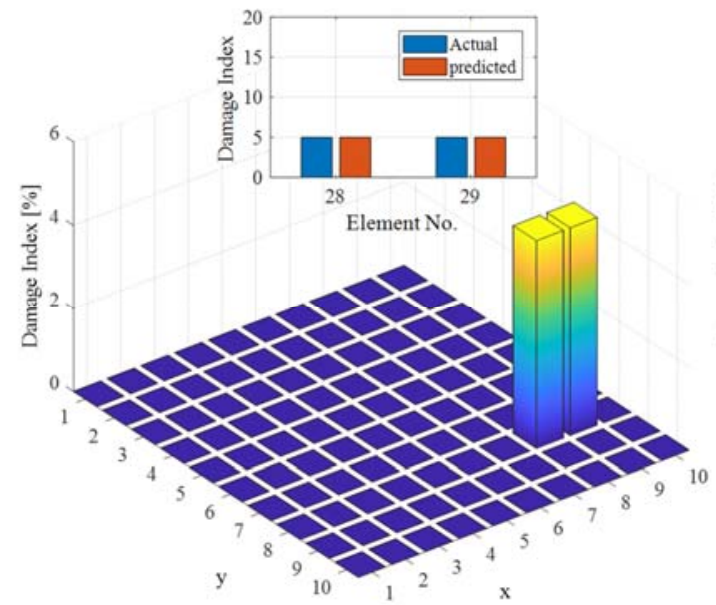

(a) Noise-free.

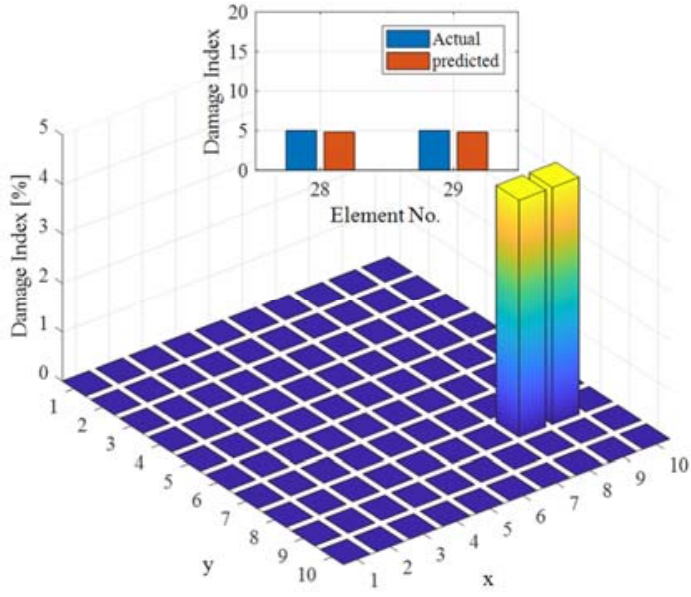

(b) Noise 3\%.

Figure 5: Damage index for all elements of the cross-ply $\left(0^{\circ} / 90^{\circ} / 0^{\circ}\right)$ square composite plate SSSS - Scenario 2.

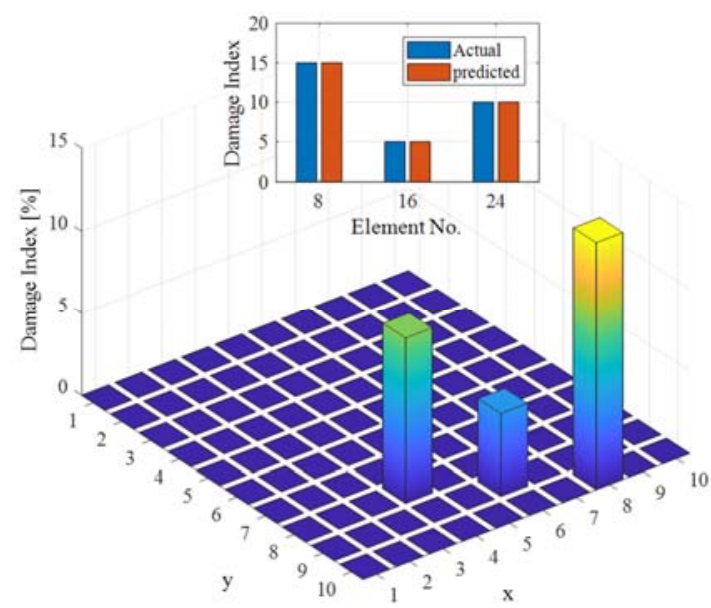

(a) Noise-free.

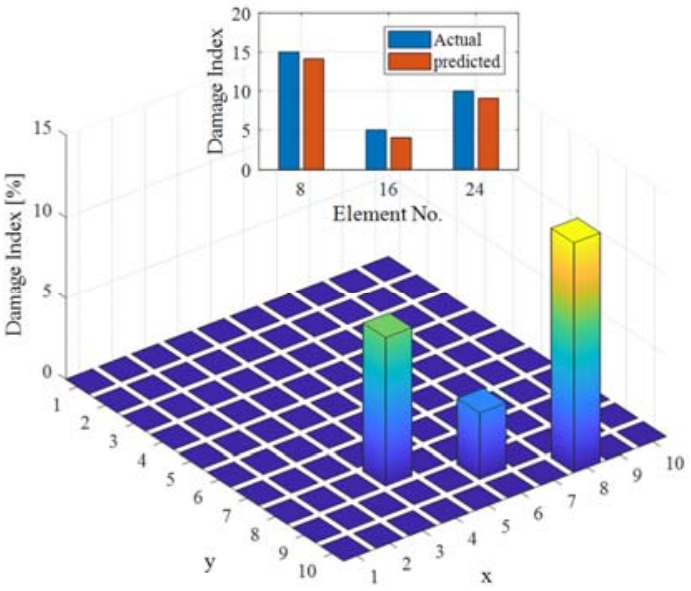

(b) Noise 3\%.

Figure 6: Damage index for all elements of the cross-ply $\left(0^{\circ} / 90^{\circ} / 0^{\circ}\right)$ square composite plate SSSS - Scenario 3. 


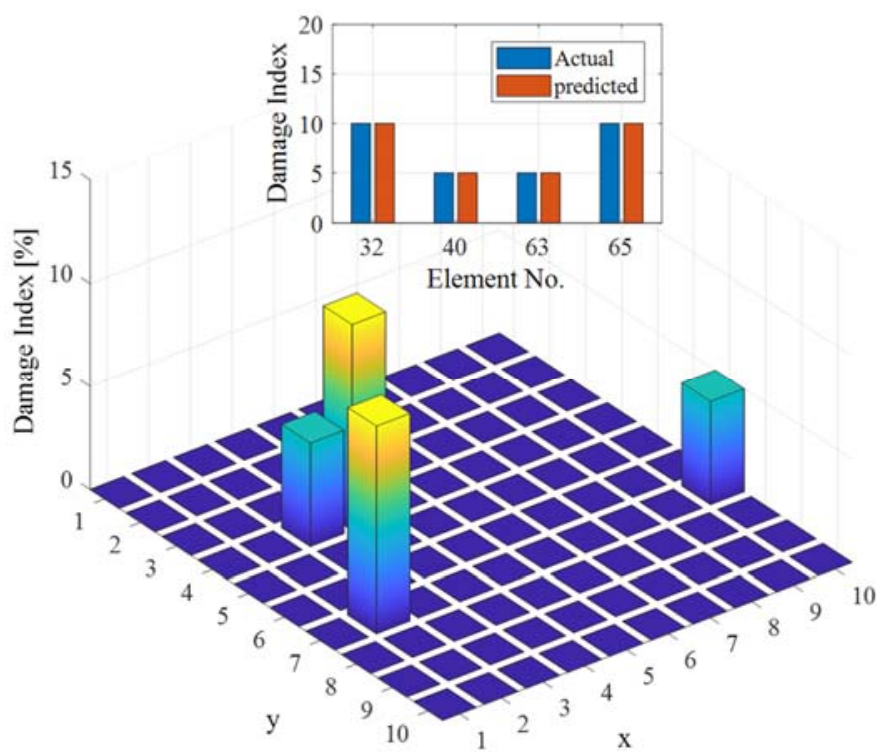

(a) Noise-free.

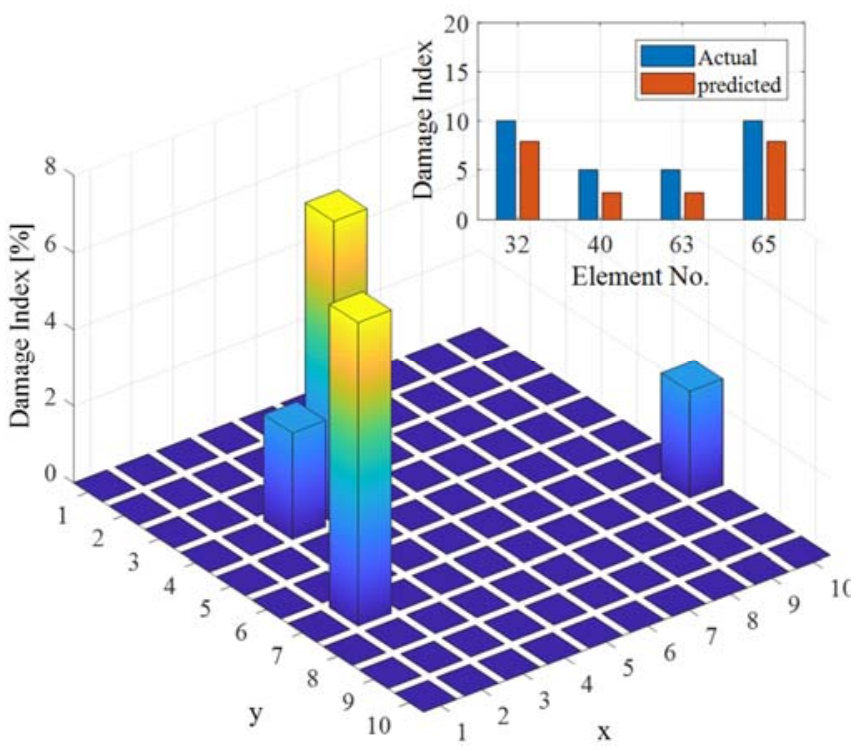

(b) Noise $3 \%$.

Figure 7: Damage index for all elements of the cross-ply $\left(0^{\circ} / 90^{\circ} / 0^{\circ}\right)$ square composite plate SSSS - Scenario 4.

The presented results showed that FRM predicts the location of damage correctly with higher accuracy in a laminated composite plate in the case of SSSS boundary conditions. On the other hand, the indicator can support the noise of up to $3 \%$. We note that prediction error under 3\% noise correlates with the number of damages. The prediction error in the case of single and double damaged plates is very small, which is noticed when the number of damages is higher than three.

Fig. 8 shows the first four mode shapes, in the case of cross-ply $\left(0^{\circ} / 90^{\circ} / 0^{\circ}\right)$ square composite plate under CCCC boundary conditions. And Figs. 9-12 plot the results of each scenario in the presence and absence of measurement noise. The natural frequencies of each damage scenario are presented in Tab. 3.

\begin{tabular}{ccccccc}
\hline & Mode & 1 & 2 & 3 & 4 & 5 \\
\multirow{3}{*}{ Intact } & {$[23] 10 \times 10$} & 4.4145 & 6.8373 & 7.6291 & 9.2078 & 10.3964 \\
& {$[24]$} & 4.4468 & 6.6419 & 7.6996 & 9.1852 & 9.7378 \\
& Present $10 \times 10$ & 4.4145 & 6.8373 & 7.6291 & 9.2078 & 10.3964 \\
\hline \multirow{3}{*}{ Damaged } & Scenario 1 & 4.4069 & 6.8359 & 7.6198 & 9.2046 & 10.3939 \\
& Scenario 2 & 4.4132 & 6.8347 & 7.6285 & 9.2060 & 10.3941 \\
& Scenario 3 & 4.4060 & 6.8299 & 7.6169 & 9.1899 & 10.3885 \\
& Scenario 4 & 4.4109 & 6.8282 & 7.6238 & 9.1976 & 10.3775 \\
\hline
\end{tabular}

Table 3: Naturel frequencies of undamaged and damaged laminated plate structure CCCC.

Under boundary condition CCCC, the indicator can support the noise of up to $3 \%$. However, the prediction error under noise is different in each scenario. The prediction error in the case of single and double damaged plates is higher than that of the cases of SSSS.

Fig. 13 summarizes the obtained damage identification results for the laminated composite plate with and without noise and the accuracy in each damage scenario. These results suggest that the scenario of plates under SSSS boundary condition correspond to the same accuracy in all cases where there is no noise. However, it has an advantage over CCCC in the scenarios of 3\% noise and three damages (Case 3). CCCC on the other hand presents an advantage in the small number of damages. 


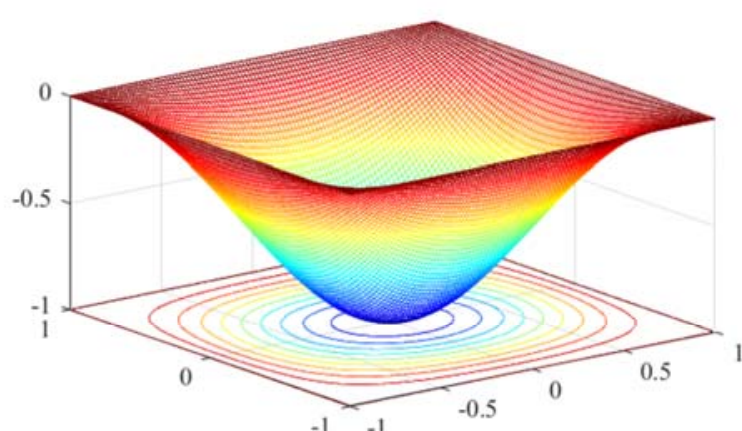

Mode 1: $\omega_{1}=4.4145 \mathrm{~Hz}$

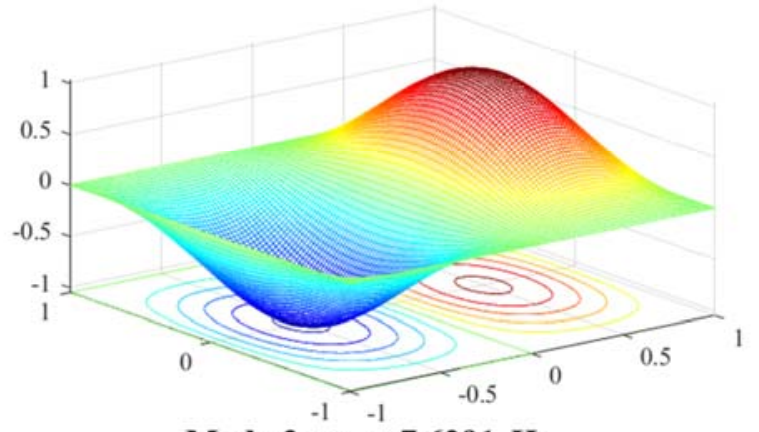

Mode 3: $\omega_{3}=7.6291 \mathrm{~Hz}$

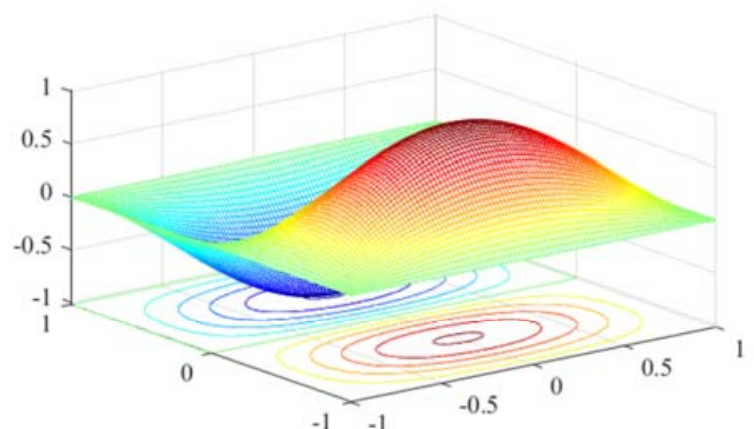

Mode 2: $\omega_{2}=6.8373 \mathrm{~Hz}$

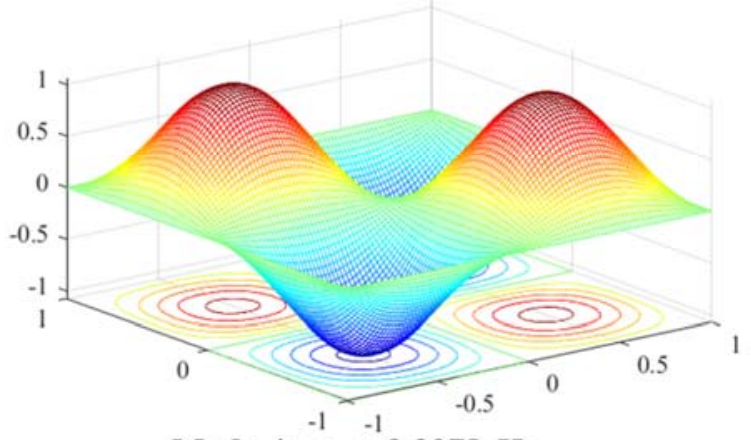

Mode 4: $\omega_{4}=9.2078 \mathrm{~Hz}$

Figure 8: The first four mode shapes of the cross-ply $\left(0^{\circ} / 90^{\circ} / 0^{\circ}\right)$ fully clamped square composite plate CCCC.

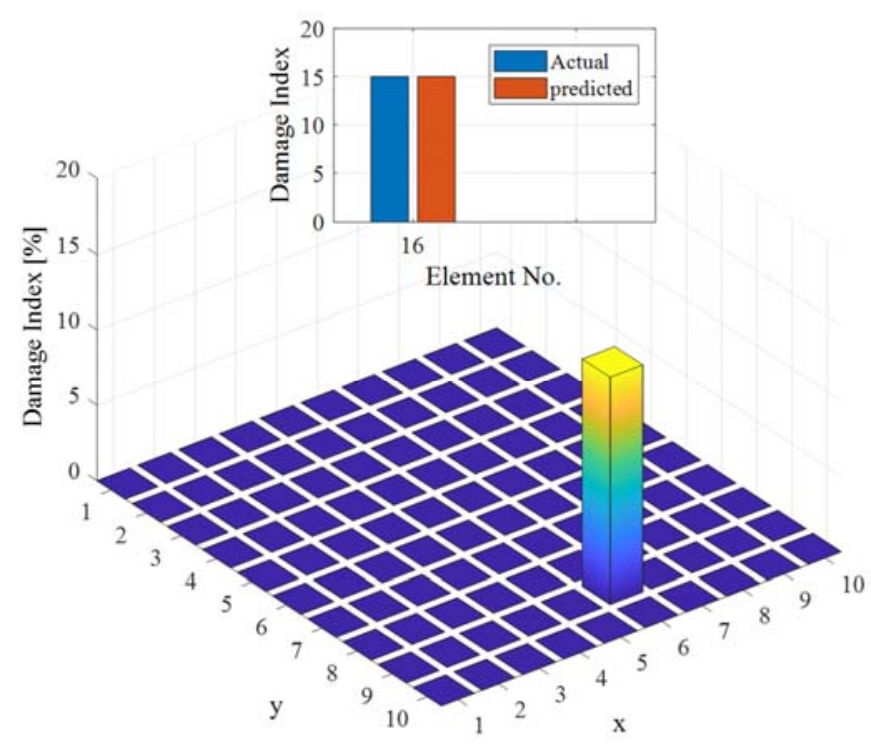

(a) Noise-free.

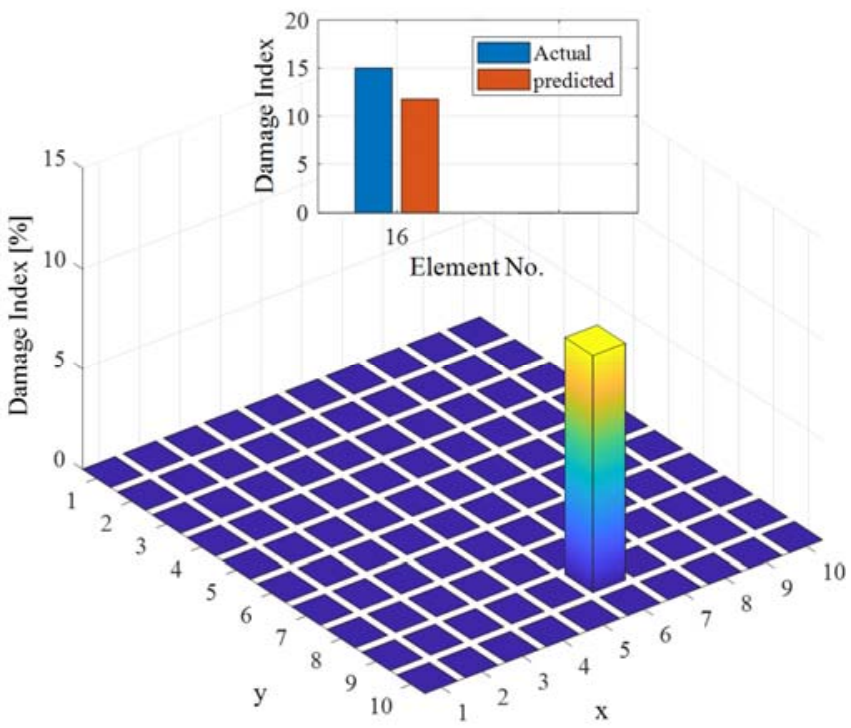

(b) Noise 3\%.

Figure 9: Damage index for all elements of the cross-ply $\left(0^{\circ} / 90^{\circ} / 0^{\circ}\right)$ square composite plate CCCC - Scenario 1. 


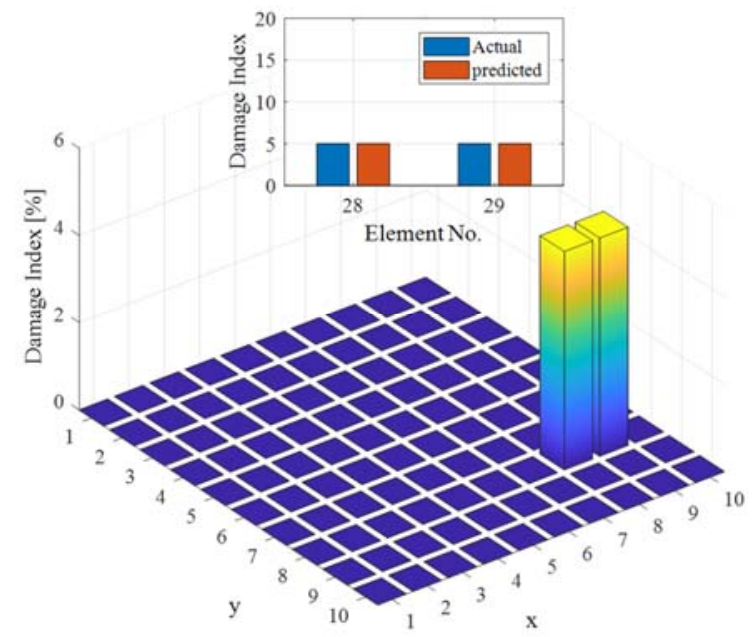

(a) Noise-free.

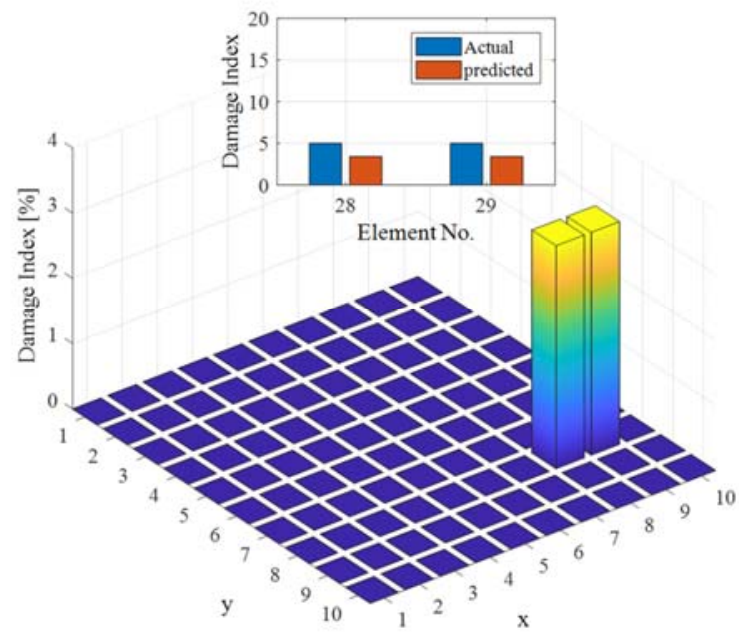

(b) Noise 3\%.

Figure 10: Damage index for all elements of the cross-ply $\left(0^{\circ} / 90^{\circ} / 0^{\circ}\right)$ square composite plate CCCC - Scenario 2.

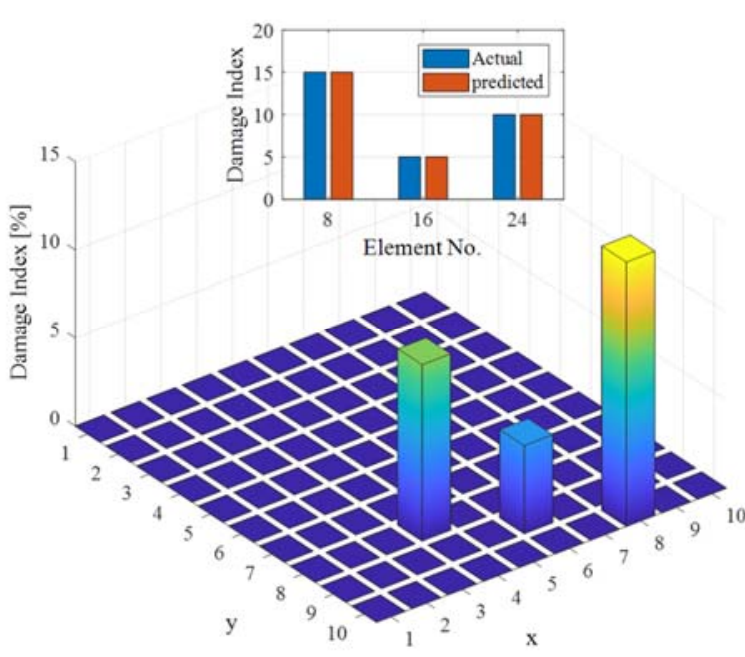

(a) Noise-free.

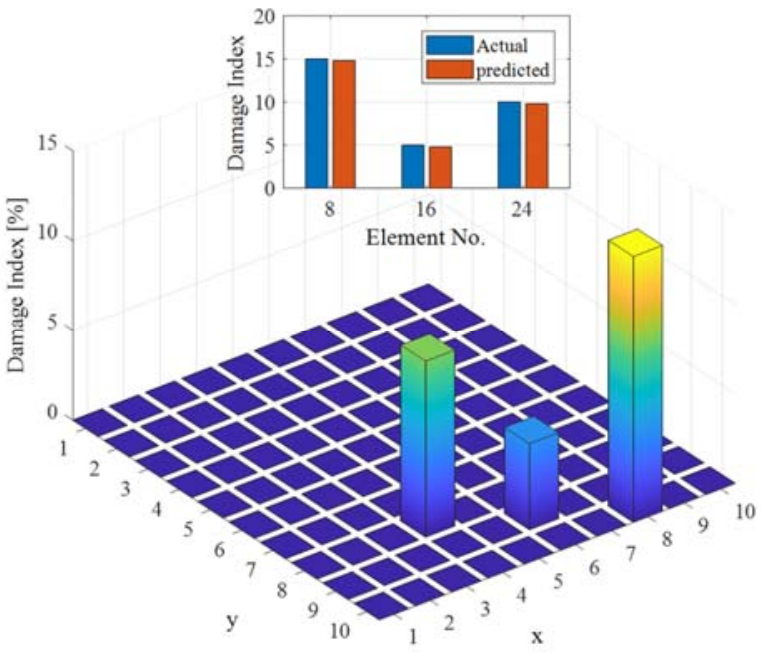

(b) Noise 3\%.

Figure 11: Damage index for all elements of the cross-ply $\left(0^{\circ} / 90^{\circ} / 0^{\circ}\right)$ square composite plate (CCCC) - Scenario 3 .

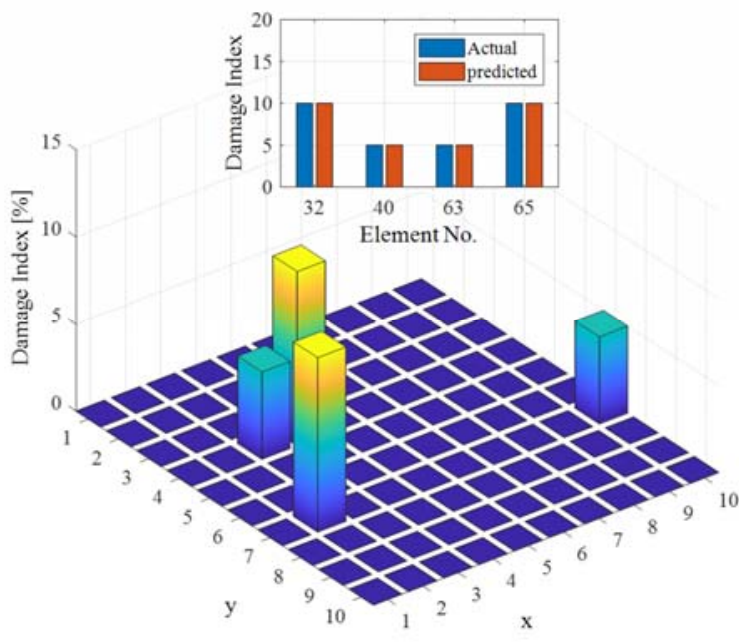

(a) Noise-free.

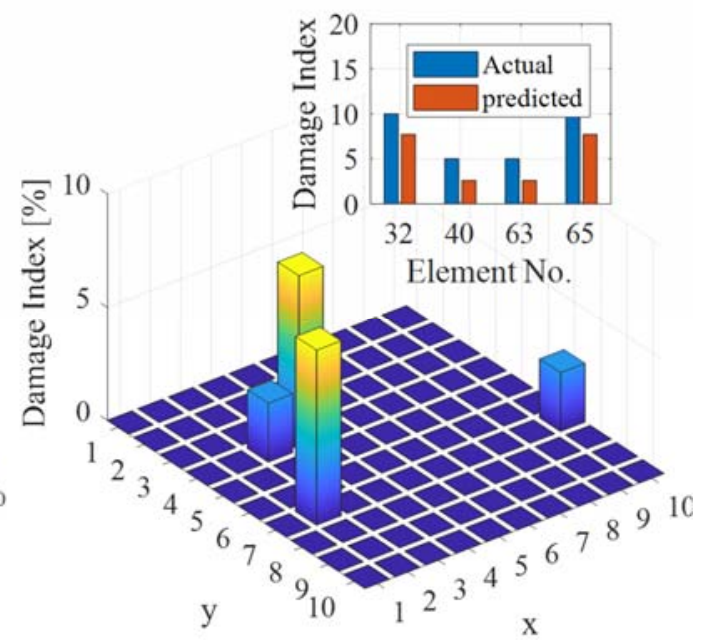

(b) Noise 3\%.

Figure 12: Damage index for all elements of the cross-ply $\left(0^{\circ} / 90^{\circ} / 0^{\circ}\right)$ square composite plate (CCCC) - Scenario 4. 

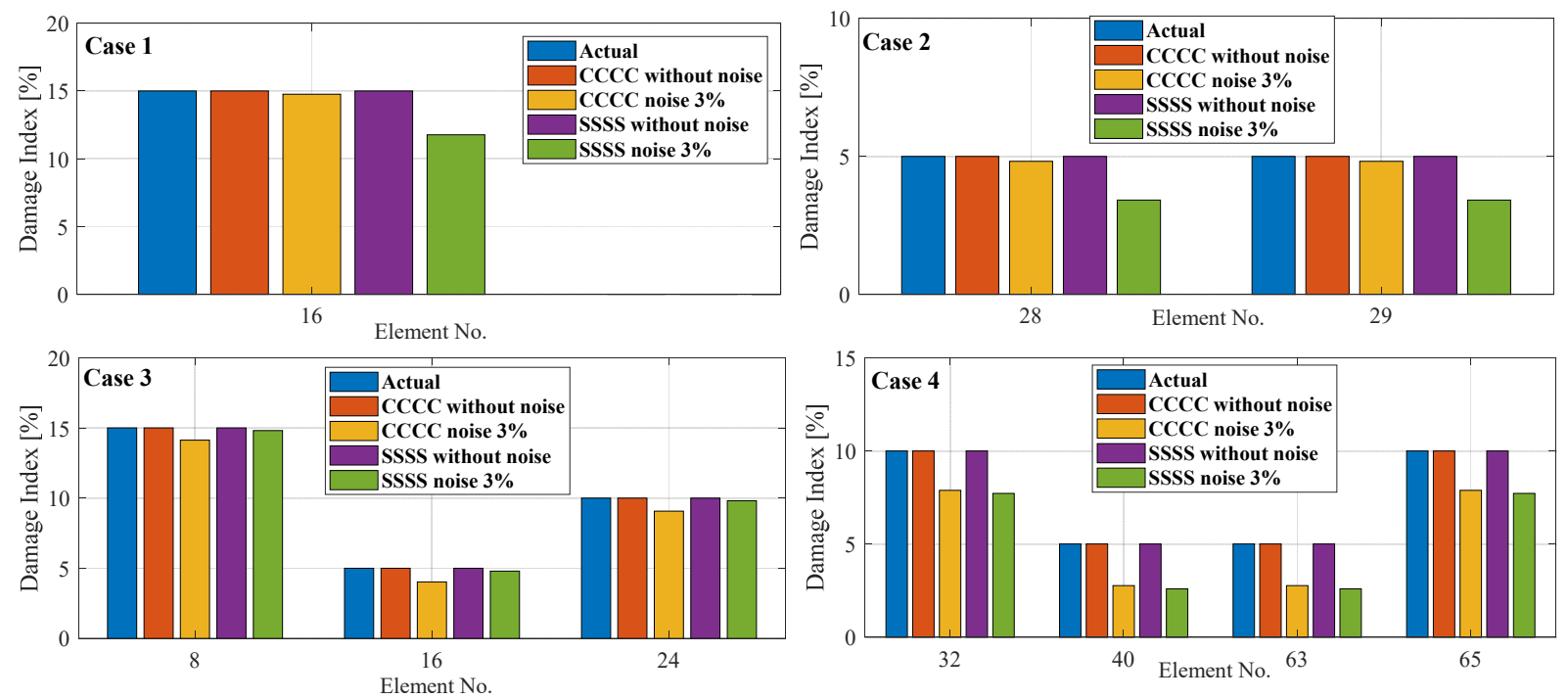

Figure 13: Comparison of obtained damage identification results for the laminated composite plat without noise and with noise.

\section{CONCLUSION}

$\mathrm{I}$ $\mathrm{n}$ this study, we present an application for damage identification based on Force Residual Method (FRM) in the case of a cross-ply $\left(0^{\circ} / 90^{\circ} / 0^{\circ}\right)$ laminated composite plate. We consider the cases of single and multiple damages, and different levels of damages. To test the accuracy of FRM, different boundary conditions were applied to the composite plate. We found that the proposed approach is accurate for damage prediction, localization, and quantification in laminated composite plates. Different levels of white Gaussian noise are applied to the measured natural frequencies and used for damage prediction for SSSS and CCCC to test the effectiveness of FRM for laminated composite. The results showed that SSSS is more stable in cases of multiple damages than CCCC, supporting noise level over 3\%.

\section{ACKNOWLEDGEMENT}

7 he fourth author, Samir Khatir, acknowledges the funding of the postdoctoral fellowship BOF20/PDO/045 provided by Bijzonder Onderzoeksfonds (BOF), Ghent University.

\section{REFERENCES}

[1] Doebling, S.W., Farrar, C.R., Prime, M.B. and Shevitz, D.W. (1996). Damage identification and health monitoring of structural and mechanical systems from changes in their vibration characteristics, a literature review. DOI: $10.2172 / 249299$.

[2] Khatir, S., Dekemele, K., Loccufier, M., Khatir, T. and Abdel Wahab, M. (2018). Crack identification method in beamlike structures using changes in experimentally measured frequencies and Particle Swarm Optimization, Comptes Rendus Mécanique, 346(2), pp. 110-120. DOI: 10.1016/j.crme.2017.11.008.

[3] Ghannadi, P. and Kourehli, S.S. (2020). Multiverse optimizer for structural damage detection: Numerical study and experimental validation, The Structural Design of Tall and Special Buildings, 29(13), pp. e1777. DOI: 10.1002/tal.1777.

[4] Wang, J. and Ni, Y. (2015). Refinement of damage identification capability of neural network techniques in application to a suspension bridge, Structural monitoring and maintenance, 2(1), pp. 77-93. DOI: 10.12989/smm.2015.2.1.077.

[5] Providakis, C., Tsistrakis, S., Voutetaki, M., Tsompanakis, Y., Stavroulaki, M., Agadakos, J., Kampianakis, E. and Pentes, G. (2015). A new damage identification approach based on impedance-type measurements and 2D error statistics, Structural Monitoring and Maintenance, 2(4), pp. 319-338. DOI: 10.12989/smm.2015.2.4.319. 
[6] Vahedian, A., Mahini, S.S. and Glencross-Grant, R. (2015). Performance-based and damage assessment of SFRP retrofitted multi-storey timber buildings, Structural monitoring and maintenance, 2(3), pp. 269-282. DOI: $10.12989 / \mathrm{smm} .2015 .2 .3 .269$.

[7] Tiachacht, S., Bouazzouni, A., Khatir, S., Abdel Wahab, M., Behtani, A. and Capozucca, R. (2018). Damage assessment in structures using combination of a modified Cornwell indicator and genetic algorithm, Engineering Structures, 177, pp. 421-430. DOI: 10.1016/j.engstruct.2018.09.070.

[8] Cawley, P. and Adams, R.D. (1979). A Vibration Technique for Non-Destructive Testing of Fibre Composite Structures, Journal of Composite Materials, 13(2), pp. 161-175. DOI: 10.1177/002199837901300207.

[9] Kessler, S.S., Spearing, S.M., Atalla, M.J., Cesnik, C.E.S. and Soutis, C. (2002). Damage detection in composite materials using frequency response methods, Composites Part B: Engineering, 33(1), pp. 87-95. DOI: $10.1016 /$ S1359-8368(01)00050-6.

[10] Hamey, C.S., Lestari, W., Qiao, P. and Song, G. (2004). Experimental Damage Identification of Carbon/Epoxy Composite Beams Using Curvature Mode Shapes, Structural Health Monitoring, 3(4), pp. 333-353.

DOI: $10.1177 / 1475921704047502$.

[11] Kumar, M., Shenoi, R.A. and Cox, S.J. (2009). Experimental validation of modal strain energies based damage identification method for a composite sandwich beam, Composites Science and Technology, 69(10), pp. 1635-1643. DOI: 10.1016/j.compscitech.2009.03.019.

[12] Khatir, S., Tiachacht, S., Thanh, C.-L., Bui, T.Q. and Abdel Wahab, M. (2019). Damage assessment in composite laminates using ANN-PSO-IGA and Cornwell indicator, Composite Structures, 230, pp. 111509.

DOI: 10.1016/j.compstruct.2019.111509.

[13] Behtani, A., Tiachacht, S., Khatir, S., Slimani, M., Mansouri, L., Bouazzouni, A. and Abdel Wahab, M. (2020), The Sensitivity of Modal Strain Energy for Damage Localization in Composite Stratified Beam Structures, Proceedings of the 13th International Conference on Damage Assessment of Structures, Singapore.

[14] Khatir, S., Tiachacht, S., Le Thanh, C., Khatir, T., Capozucca, R. and Abdel Wahab, M. (2020), Damage Detection in Laminated Composite Plates Based on Local Frequency Change Ratio Indicator, Proceedings of the 13th International Conference on Damage Assessment of Structures, Singapore.

[15] Nobahari, M. and Seyedpoor, S.M. (2013). An efficient method for structural damage localization based on the concepts of flexibility matrix and strain energy of a structure, Structural engineering and mechanics: An international journal, 46(2), pp. 231-244. DOI: 10.12989/sem.2013.46.2.231.

[16] Pandey, A.K. and Biswas, M. (1994). Damage Detection in Structures Using Changes in Flexibility, Journal of Sound and Vibration, 169(1), pp. 3-17. DOI: 10.1006/jsvi.1994.1002.

[17] Ghannadi, P., Kourehli, S.S., Noori, M. and Altabey, W.A. (2020). Efficiency of grey wolf optimization algorithm for damage detection of skeletal structures via expanded mode shapes, Advances in Structural Engineering, 23(13), pp. 2850-2865. DOI: $10.1177 / 1369433220921000$.

[18] Khatir, S., Abdel Wahab, M., Boutchicha, D. and Khatir, T. (2019). Structural health monitoring using modal strain energy damage indicator coupled with teaching-learning-based optimization algorithm and isogoemetric analysis, Journal of Sound and Vibration, 448, pp. 230-246. DOI: 10.1016/j.jsv.2019.02.017.

[19] Khatir, S. and Abdel Wahab, M. (2019). Fast simulations for solving fracture mechanics inverse problems using PODRBF XIGA and Jaya algorithm, Engineering Fracture Mechanics, 205, pp. 285-300. DOI: 10.1016/j.engfracmech.2018.09.032.

[20] Khatir, S., Belaidi, I., Serra, R., Wahab, M.A. and Khatir, T. (2015). Damage detection and localization in composite beam structures based on vibration analysis, Mechanics, 21(6), pp. 472-479. DOI: 10.5755/j01.mech.21.6.12526.

[21] Reddy, J.N. (2003) Mechanics of laminated composite plates and shells: theory and analysis. CRC press. DOI: $10.1201 / \mathrm{b} 12409$.

[22] Shen, J.Y. and Sharpe Jr., L. (2000), Damage detection using residual modal forces and modal sensitivity, Proceeding of 14th ASCE Engineering Mechanics Conference.

[23] Ferreira, A.J.M. and Fasshauer, G.E. (2007). Analysis of natural frequencies of composite plates by an RBFpseudospectral method, Composite Structures, 79(2), pp. 202-210. DOI: 10.1016/j.compstruct.2005.12.004.

[24] Liew, K.M. (1996). Solving the vibration of thick symmetric laminates by reissner/mindlin plate theory and the p-ritz method, Journal of Sound and Vibration, 198(3), pp. 343-360. DOI: 10.1006/jsvi.1996.0574. 